\title{
Management of the failing Fontan circulation
}

\author{
Barbara J Deal, ${ }^{1}$ Marshall L Jacobs ${ }^{2}$
}

\begin{abstract}
- Additional references are published online only. To view these references please visit the journal online (http://heart.bmi. com/content/98/14.toc)

${ }^{1}$ Division of Cardiology, Children's Memorial Hospital, Feinberg School of Medicine, Northwestern University, Chicago, Illinois, USA ${ }^{2}$ Department of Pediatric and Congenital Heart Surgery, Center for Pediatric and Congenital Heart Disease, Cleveland Clinic Foundation, Cleveland, Ohio, USA
\end{abstract}

\section{Correspondence to}

Dr Barbara J Deal, Division of Cardiology, Children's Memorial Hospital, 2300 Children's Plaza, mc 21, Chicago, IL 60614, USA; bdeal@childrensmemorial.org

\section{UNLOCK:1}

This paper is freely available online under the BMJ Journals unlocked scheme, see http:// heart.bmi.com/site/about/ unlocked.xhtml
The 'Fontan circulation' has evolved to include a variety of surgical procedures designed to overcome the absence of two distinct ventricular chambers. ${ }^{1}$ w1-w3 Inherent to this circulation is chronic elevation of right atrial and vena caval pressure, and absence of a dedicated power source to serve the pulmonary circulation, making low pulmonary vascular resistance and optimal systemic ventricular function the essential ingredients of a successful Fontan circulation. ${ }^{2}$ Originally designed for the single left ventricle, modifications to the original atriopulmonary connections extended repairs to complex ventricular anatomy, and are now most commonly performed for single right ventricular anatomy associated with hypoplastic left heart syndrome. Together with improved perioperative management, creation of the Fontan circulation in two stages (superior cavopulmonary anastomosis followed by later Fontan completion ${ }^{\mathrm{w}} 4$ ), and performance of Fontan procedures at a younger age, have led to reduced operative mortality associated with the Fontan procedure of $\leq 5 \%$ (compared with $15-30 \%$ in earlier decades); survival at 20 years is presently $85 \%{ }^{3}$ w5

Over the last two decades, the initial survivors of the atriopulmonary Fontan repairs have reached adulthood, bringing a multiplicity of haemodynamic complications and sequelae of their abnormal circulatory status. The atriopulmonary connection is now obsolete as a surgical option, and the current surviving adults with this circulation do not reflect contemporary Fontan outcomes. Nonetheless, their attendant compendium of complications and sequelae provides a daunting array of management challenges, and stigmatises the current perception of long term Fontan outcomes.

The 'Fontan circulation' now encompasses a spectrum of anatomic substrates, staging options, and operative techniques. Problems classified as 'Fontan failure' may represent problems inherent to the morphologic substrate, operative variables, and inevitable sequelae of the Fontan circulation: chronic venous congestion and progressively declining functional status. This review will separate complications into those where intervention may optimise clinical status while maintaining the Fontan circulation - the 'failing Fontan'-and those conditions which have progressed to a 'failed Fontan', where options are limited to cardiac transplantation or attempts to minimise the impact of irreversible functional deterioration.
Finally, we will discuss strategies which may alter the incidence and time course of Fontan failure.

\section{THE FAILING FONTAN CIRCULATION}

Evaluation of the failing or failed Fontan circulation requires knowledge of the anatomic substrate, surgical intervention details, cardiac imaging and assessment of haemodynamic status, assessment of rhythm status, and evaluation of other organ systems and metabolic function. Late Fontan failure may present insidiously over years. It is a failure of medical management to interpret the absence of overt symptoms or ascites as evidence of optimal haemodynamic status in the functionally univentricular circulation. In contrast to other forms of operated congenital heart disease, Fontan patients have lived with less than ideal cardiac output their entire lives, and may neither recognise nor show overt manifestations of progressive decline in functional status until deterioration is quite advanced (table 1).

\section{Growth}

In general, the Fontan patient population is shorter in height than the normal population; there is increased recognition that failure to gain weight appropriately is an early indicator of suboptimal cardiac output in childhood. ${ }^{4}$ Growth failure should prompt a thorough investigation of haemodynamic status, with early efforts to optimise haemodynamic status with catheter or surgical intervention for residual obstruction or valve abnormalities.

Exercise capacity is lower in Fontan patients than in other patients with repaired congenital heart disease, and recent studies have reported a $1-3 \%$ annual decline in maximal oxygen consumption beginning in adolescence..$^{56-w 8}$ In Fontan patients, the average peak oxygen consumption ranges from $19-28 \mathrm{ml} / \mathrm{kg} / \mathrm{min}$, or $50-60 \%$ of predicted consumption for age. Decline in exercise function correlates with the need for hospitalisation and symptom development. ${ }^{6}$ w8 Decreased exercise tolerance is more common in single right or indeterminant ventricular morphology, and in patients with lateral tunnel repairs, and may be related to chronotropic incompetence or abnormal pulmonary compliance with exertion. ${ }^{6}$ w8 w9 Serial exercise testing may objectively identify changes in haemodynamic or rhythm status, which may be addressed with intervention such as pulmonary stenting, atrial 
Table 1 Failing Fontan circulation

\begin{tabular}{|c|c|c|}
\hline \multirow[t]{3}{*}{ Constitutional } & Growth failure & Inadequate cardiac output \\
\hline & Exercise intolerance & Chronotropic incompetence, pronounced atrial distension \\
\hline & Depression & Secondary to limitations on functional status \\
\hline \multirow[t]{6}{*}{ Haemodynamic } & Obstruction & Atriopulmonary, pulmonary arterial \\
\hline & Systemic venous & Pulmonary venous return, atrioventricular (AV) valve inflow \\
\hline & Systemic outflow & Ventricular outflow, aortic arch \\
\hline & AV valve function & $\begin{array}{l}\geq \text { Moderate regurgitation } \\
\geq \text { Mild stenosis }\end{array}$ \\
\hline & Ventricular dysfunction & $\begin{array}{l}\text { Secondary: atrial dilatation/distortion; AV valve or semilunar valve dysfunction, chronic arrhythmias } \\
\text { or antiarrhythmic medications; impaired myocardial perfusion due to coronary sinus hypertension }\end{array}$ \\
\hline & Thrombosis & Systemic venous, atrial, pulmonary \\
\hline Rhythm & Arrhythmias & $\begin{array}{l}\text { Sinus node dysfunction, predominant junctional rhythm, AV block, supraventricular tachycardia/atrial } \\
\text { tachycardia, ventricular tachycardia }\end{array}$ \\
\hline \multirow[t]{2}{*}{ Pulmonary } & Cyanosis & Intracardiac right to left shunt, veno-venous collaterals, pulmonary arteriovenous malformations (AVMs) \\
\hline & Pleural effusions & \\
\hline Gastrointestinal & Ascites & Secondary to portal hypertension related to obstruction, versus cirrhosis \\
\hline Metabolic & Metabolic markers & Declining albumin; thrombocytopenia; hyperbilirubinaemia; coagulopathy \\
\hline
\end{tabular}

pacing, pulmonary vasodilator therapy, or Fontan conversion surgery. ${ }^{5}$

\section{Cyanosis}

A mild degree of desaturation is present in most Fontan patients, due to coronary sinus drainage to the left atrium or pulmonary shunting. Resting saturations $<90 \%$ suggest the presence of right to left shunting (either intracardiac or due to venoveno collateral flow to the left atrium) or pulmonary arteriovenous fistulae. Coil embolisation of collaterals or catheter based occlusion of atrial septal defects may improve saturations, although investigation for a more compelling cause for the development of collaterals may allow more definitive intervention. Patients with discontinuous pulmonary arteries with a classic Glenn to the right pulmonary artery have insufficient hepatic flow to that lung, and would benefit from surgical intervention to provide confluent pulmonary arteries and increased hepatic flow to the right lung. Patients with atriopulmonary connections frequently have 'decompressing' collateral flow or atrial level shunts, and benefit from Fontan conversion.

\section{Pathway obstructions and valve dysfunction}

The development of haemodynamic abnormalities may be gradual and insidious in Fontan patients, and detection is complicated by the lack of complaints from most patients until pronounced limitation occurs. Decline in exercise tolerance, resting or exercise desaturation, the presence of a murmur, hepatomegaly, or cardiomegaly on radiography are indicators of haemodynamic abnormalities. Patients with atriopulmonary connections develop marked right atrial distension over time, secondary to anatomic obstructions at the anastomosis, or due to the notable energy loss associated with sluggish flow (figure 1). Decompression of the atrium occurs via coronary sinus dilatation, and atrial communications or veno-veno collaterals from the systemic veins to the left atrium or pulmonary veins may ensue. Distension of the right atrium may result in torsion and narrowing of the connection to the pulmonary arteries, as well as compression of the pulmonary venous return from the right lung; the dilated atrium may impinge on inflow in the setting of a right-sided atrioventricular valve. Anatomic obstructions may exist at the atriopulmonary anastomosis or the branch pulmonary arteries; a gradient of $>1 \mathrm{~mm} \mathrm{Hg}$ in this circuit dependent on passive flow is haemodynamically significant. Patients with valved conduits in place, either atrioventricular or atriopulmonary, invariably develop obstruction over time. Patients with lateral tunnel repairs in general do not develop pronounced atrial distension, but narrowing at the pulmonary arteries may exist. Abnormalities of atrioventricular (AV) valve function result in elevated left atrial pressure, which will harm the pulmonary circulation. Chronic aortic outflow obstruction will result in hypertrophy and diminished ventricular compliance; the volume overload of aortic insufficiency will contribute to ventricular failure.

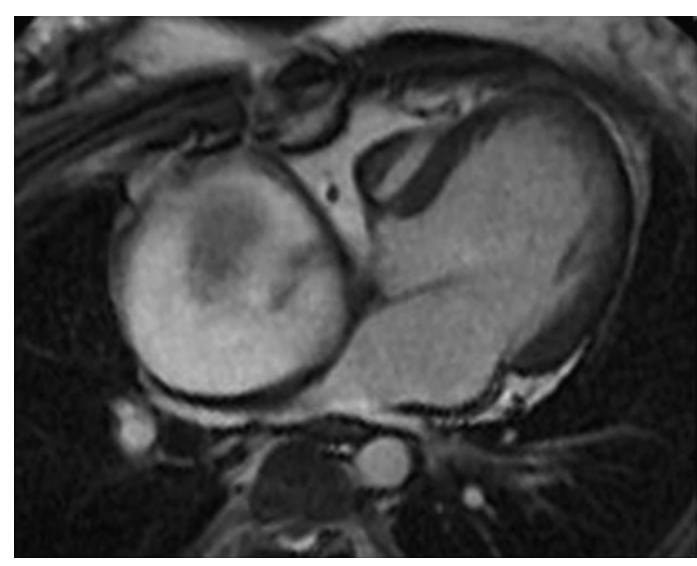

Figure $1 \mathrm{MRI}$ of marked atrial dilatation with impingement on pulmonary venous return in a patient with an atriopulmonary Fontan anastomosis for tricuspid atresia. Right atrium measures $7 \times 7.5 \mathrm{~cm}$. Image courtesy of Cynthia K Rigsby, Children's Memorial Hospital, Chicago, Illinois, USA. 
Hepatic and infra-diaphragmatic venous congestion is present in all Fontan patients, to greater or lesser degrees. Sequestration of platelets by the liver and spleen result in thrombocytopenia, present in $15-25 \%$ of adult Fontan patients. Mild elevation of bilirubin is common, followed by abnormalities of liver enzymes. The effects of years of venous congestion will result in hepatic cirrhosis, which becomes apparent by approximately 11 years following surgery. ${ }^{7}$ Surveillance with abdominal ultrasound may detect hepatic nodules, with more detailed imaging provided by CT. Monitoring of $\alpha$ fetoprotein may provide early detection of hepatocellular carcinoma, now reported in a small number of older Fontan patients.

\section{Arrhythmias}

This broad term includes sinus node dysfunction, predominant junctional rhythm, atrioventricular block, supraventricular and ventricular arrhythmias, and the risk of arrhythmic sudden death. Modifications to the Fontan procedure have resulted in a decreased incidence of sinus node dysfunction and atrial arrhythmias. Sinus node dysfunction is reported in $40 \%$ of patients with atriopulmonary connections, and is reported in up to $25 \%$ of lateral tunnel and extracardiac cavo-

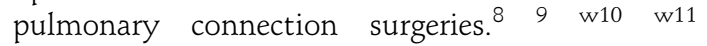
Reassurance based on an 'adequate overall heart rate', which is usually junctional, is a disservice to the patient, as the haemodynamic consequences of junctional rhythm in the Fontan circulation are profound, including acute elevation of atrial pressure with each ventricular contraction. Non-sinus rhythm has been associated with increased risk of atrial arrhythmias, as well as an increased risk of hepatic fibrosis ${ }^{\mathrm{w} 12}$; these data warrant vigorous attempts to maintain regular atrial rhythm in Fontan patients.

The incidence of atrial arrhythmias during long term follow-up has decreased with surgical modi- fications of the Fontan procedure, from as many as $60 \%$ of atriopulmonary patients to approximately $12 \%$ of extracardiac total cavopulmonary connection patients. ${ }^{9-13}$ w5 w13 Atrial reentrant tachycardia accounts for approximately $75 \%$ of supraventricular tachycardia, with focal atrial tachycardia in up to $15 \%$ of patients. ${ }^{\text {w13 }}$ w14 In lateral tunnel patients, the reentrant circuit may reside in the pulmonary venous atrium. Atrial fibrillation is becoming increasingly common in adult Fontan patients, and is present in almost half of patients referred for Fontan conversion. Risk factors for the development of atrial tachycardia include an atriopulmonary connection, preoperative bradycardia, lack of sinus rhythm, older age at Fontan and longer postoperative interval, greater than mild atrioventricular valve regurgitation, and heterotaxy syndrome. ${ }^{3} 11 \mathrm{w} 11$ As the incidence of atrial tachycardia increases with the postoperative interval and is a major source of morbidity, ${ }^{8} 10$ regular surveillance of rhythm with ambulatory $24 \mathrm{~h}$ monitors, event monitors and exercise testing becomes more important during long term followup.

Termination of an acute episode of atrial tachycardia within 24-48 h from onset is recommended whenever possible, due to the rapid deterioration in haemodynamic status associated with tachycardia in the single ventricle circulation. Figure 2 summarises an algorithm for management of atrial arrhythmias. ${ }^{\text {w15 }}$ Development of atrial tachycardia is commonly associated with haemodynamic abnormalities which will require more extensive haemodynamic, functional, and metabolic evaluation. Catheter ablation for atrial tachycardia in Fontan patients has considerably lower success rates than in other forms of repaired congenital heart disease. Acute success rates from catheter ablation in the Fontan patient range from $40-75 \%$, with recurrence of tachycardia in $60 \%$ of patients during the first year. ${ }^{14}$ w14 Catheter ablation in this

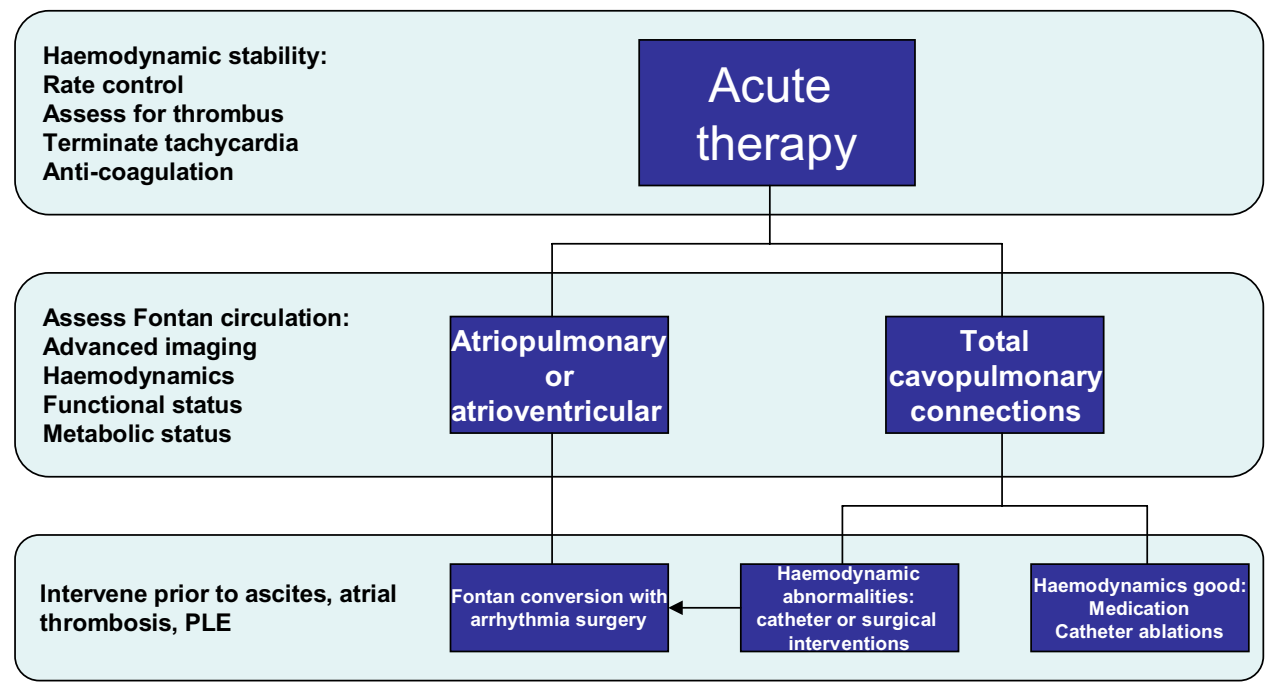

Figure 2 Management of atrial arrhythmias in Fontan patients. PLE, protein-losing enteropathy. 
population is best suited for patients with lateral tunnel repairs and focal atrial tachycardia, or atriopulmonary repairs who are not suitable candidates for Fontan arrhythmia surgery. The development of significant arrhythmias in the atriopulmonary or atrioventricular Fontan modification, when coupled with signs of heart failure, is associated with a 3 year mortality rate of $25 \%$.

\section{Fontan conversion with arrhythmia surgery}

Recognition that atriopulmonary Fontan patients have associated haemodynamic limitations in addition to atrial tachycardia led our group to incorporate arrhythmia surgery into Fontan conversion to an extracardiac total cavopulmonary connection, beginning in $1994 .{ }^{15} \mathrm{w} 16$ In addition to right atrial reduction, performance of a modified right atrial maze procedure eliminates right atrial macro-reentrant tachycardia, but is not intended to treat focal atrial tachycardia or other mechanisms without targeted resection (figure 3). Left atrial macro-reentrant tachycardia or atrial fibrillation is treated with an additional left atrial Cox Maze III, which effectively eliminates atrial fibrillation, but we have noted recurrence of a slower organised atrial reentry tachycardia in about $15 \%$ of such patients. ${ }^{\text {w16 }}$ Implantation of epicardial dual

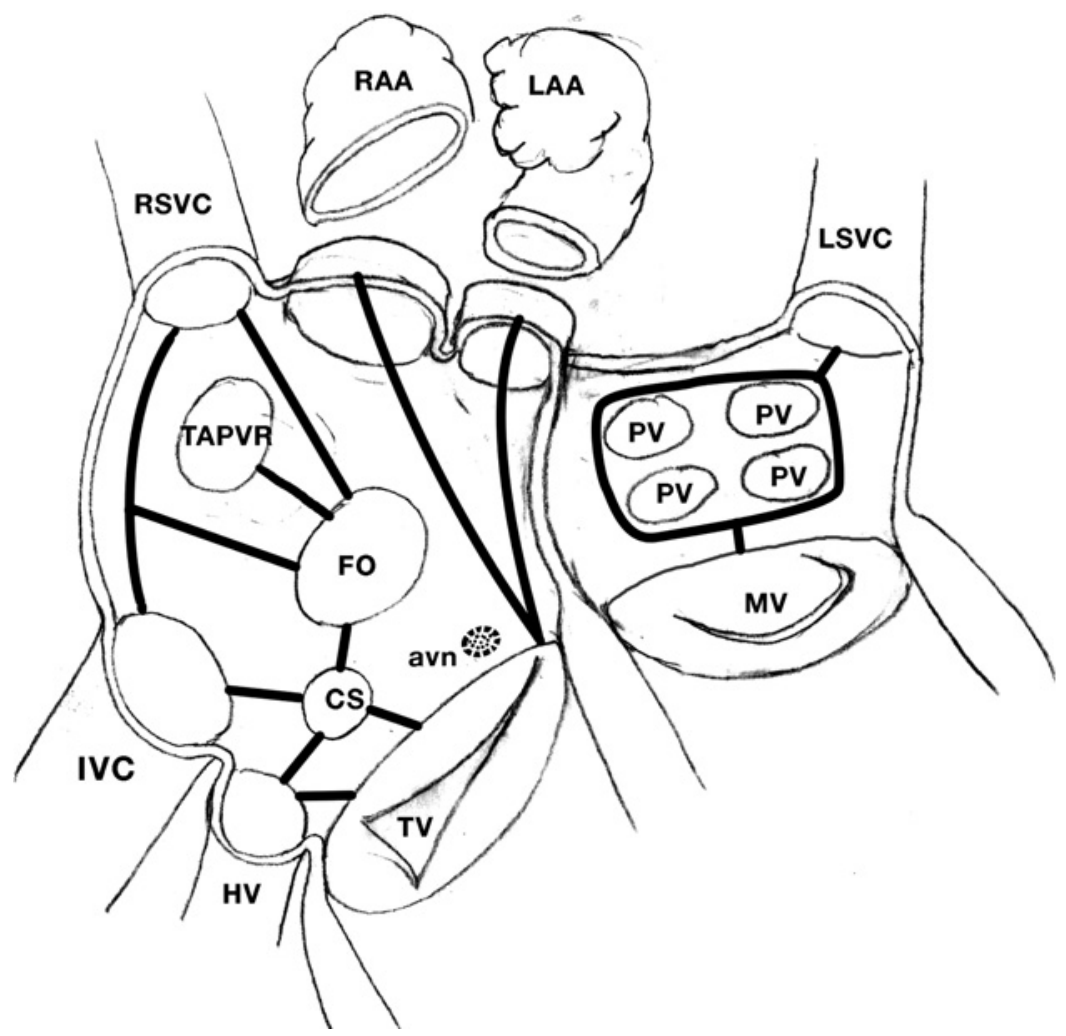

Figure 3 Surgical modifications of atrial maze procedure in complex anatomy. Solid black lines indicate sites of cryoablation. avn, atrioventricular node; CS, coronary sinus; FO, foramen ovale; HV, hepatic vein; IVC, inferior vena cava; LAA, left atrial appendage; LSVC, left superior vena cava; MV, mitral valve; PV, pulmonic vein; RAA, right atrial appendage; RSVC, right superior vena cava; TAPVR, total anomalous pulmonary venous return; TV, tricuspid valve. Reprinted with permission from Mavroudis C, Deal BJ, Backer $\mathrm{CL}$, Tsao S. Arrhythmia surgery in patients with and without congenital heart disease. Ann Thorac Surg 2008;86:857-68. chamber anti-tachycardia pacing systems is performed for virtually all patients, predominantly relying on atrial pacing at rates of $70-80$ beats $/ \mathrm{min}$ chronically, without ventricular pacing. Our centre has performed over 135 Fontan conversions with arrhythmia surgery at a mean interval of $15.5 \pm 5.2$ years following initial Fontan procedure, with acute mortality of $1.5 \%$; other centres have achieved relatively comparable results. ${ }^{16}$ Analysis of intermediate outcomes in the initial 110 patients undergoing such surgery at our centre showed freedom from death or transplantation at 15 years of follow-up was $80 \%$, with freedom from recurrent tachycardia of $85 \%$. Risk factors for poor outcomes in this population include right or ambiguous ventricle, presence of right atrial thrombus at time of surgery, older age at Fontan conversion, longer post-Fontan interval, or ascites. Patients with protein-losing enteropathy are not considered candidates for Fontan conversion surgery, and patients without correctable causes of poor ventricular function, or multiorgan system disease, may be better treated by transplantation. We have recently demonstrated improved functional status at 5 years of follow-up in a subset of patients undergoing paired pre- and post-Fontan conversion exercise testing, with an average $17 \%$ increase in maximal oxygen consumption. These results suggest that aggressive efforts to improve flow dynamics and associated haemodynamic abnormalities, eliminate arrhythmias, and maintain chronic atrial rhythm may favourably alter what has been considered as an 'inexorable decline' in functional status in many Fontan patients.

In addition to atrial arrhythmias, atrioventricular block occurs, either due to intrinsic conduction abnormalities as seen in patients with L-transposition, or as a consequence of surgery. The incidence of pacemaker implantation in most series ranges from $3-18 \%$, without stratification as to implantation for AV block versus sinus node dysfunction. ${ }^{3}$ w5 w17 Limitations of venous access to the atrium, the risk of endocardial lead thrombosis, and the morbidity of repeat sternotomy to place epicardial leads, support a preemptive strategy of atrial lead placement at the time of primary Fontan repair, although not a class I or II indication for pacing by current recommendations. With improved survival, it is becoming apparent that ventricular arrhythmias are noted in $3-12 \%$ of adult patients. ${ }^{17}$ w5 w17 The contribution of ventricular arrhythmias to late sudden death, reported in $9 \%$ of patients, is not yet known. ${ }^{18}$

\section{Ascites}

Ascites may develop as a consequence of elevated right atrial pressure, protein-losing enteropathy or hepatic dysfunction, and requires clarification of the aetiology with aggressive evaluation and treatment. Ascites may occur without hypoalbuminaemia, but is an advanced indicator of a failing Fontan circulation; in this setting, Fontan conversion with arrhythmia surgery may be feasible, although with increased risk of later 
Fontan failure. A small number of patients have persistent or recurrent ascites late after Fontan conversion, without evidence of Fontan circulation obstruction. In this setting, ascites is thought to be related to hepatic dysfunction. Diuretic therapy and optimisation of medical therapy may minimise ascites; regular evaluation of cirrhotic changes with abdominal ultrasound, CT or MRI, and monitoring of liver function, is recommended. When advanced cardiac liver cirrhosis changes are noted, the risk for hepatocellular carcinoma increases. ${ }^{7}$ Combined cardiac and liver transplantation for a Fontan patient has been performed successfully. ${ }^{\text {w18 }}$

\section{THE FAILED FONTAN}

In the unusual setting of early postoperative failure, a failed circulation requires early takedown of the Fontan surgical circuit. Late failure, discussed here, includes haemodynamic or multiorgan system complications of the Fontan circulation which are not reversible by surgical or catheter interventions at acceptable risk. Strategies to minimise/palliate complications or consideration for cardiac transplantation are the limited therapeutic options. Table 2 summarises the conditions associated with a failed Fontan, which are discussed in several excellent reviews. ${ }^{19}$ w19 Most studies report early operative mortality for Fontan patients undergoing cardiac transplantation at approximately $30 \%$, higher than that reported for other forms of congenital heart disease, ${ }^{20}$ although one recent study showed no difference in early mortality among Fontan patients. ${ }^{\text {w20 }}$ Problems specific to the Fontan patient undergoing transplantation include multiple prior surgeries with increased sensitisation rates between $20-60 \%$, with preformed antibodies to donor human leucocyte antigens (HLA), complexities of venous anatomy, malnourishment associated with protein-losing enteropathy, and acute graft right heart failure. After the early transplant period, there is no difference in long term survival compared with other forms of congenital heart disease, with survival rates at 10 years of around $54 \%$. ${ }^{\text {w2 }}{ }^{\text {w } 22}$ Due to the significant mortality on the waiting list and elevated early mortality, there is interest in developing implantable mechanical assist devices in Fontan patients as either a bridge to transplantation, or 'destination therapy'. w23 w24

\section{FAILURE OF MEDICAL CARE}

At this stage in our knowledge of the natural history of the Fontan circulation, several concepts have become clear, including: (1) the unique challenges of the functionally univentricular circulation with progressive multiorgan system impact; (2) the inability to definitively treat a truly 'failed' Fontan with measures other than cardiac transplantation; (3) the inadequacy of traditional cardiac follow-up visits to reliably detect subtle changes in circulation before advanced stages; and (4) the challenges in 'cardiac' management that present unlike any other repaired congenital cardiac anomalies. In addition,

Table 2 Failed Fontan circulation

\begin{tabular}{|c|c|c|c|c|}
\hline Condition & Incidence & Manifestations & Aetiologies & Treatments \\
\hline Early failure & $3 \%$ & $\begin{array}{l}\text { Low cardiac output, } \\
\text { pleural effusions, } \\
\text { chylothoraces, ascites, } \\
\text { hepatomegaly }\end{array}$ & $\begin{array}{l}\text { Pulmonary vasculature abnormalities } \\
\text { Incessant/refractory atrial tachycardia } \\
\text { Residual obstruction related to } \\
\text { surgical technique }\end{array}$ & $\begin{array}{l}\text { Early evaluation to correct } \\
\text { obstructions, terminate tachycardia } \\
\text { Fontan takedown } \\
\text { Recreate systemic to pulmonary blood flow } \\
\text { Cardiac transplantation }\end{array}$ \\
\hline $\begin{array}{l}\text { Late failure } \\
\text { Lymphatic dysfunction } \\
\text { Protein-losing enteropathy (PLE) }\end{array}$ & $2-13 \%$ & $\begin{array}{l}\text { Ascites, peripheral oedema, } \\
\text { pleural effusions, diarrhoea, } \\
\text { malabsorption of fat, } \\
\text { hypoalbuminaemia }\end{array}$ & $\begin{array}{l}\text { Unknown, but associated with: } \\
\text { Low cardiac output } \\
\text { Mesenteric vascular flow abnormalities } \\
\text { Intestinal cellular wall damage } \\
\text { Autoimmune reactions } \\
\text { Intestinal lymphangiectasia } \\
\text { Risk factors: prolonged postoperative chest } \\
\text { tube drainage, systemic right ventricle }\end{array}$ & $\begin{array}{l}\text { Nutritional support with protein and medium } \\
\text { chain triglycerides } \\
\text { Optimise cardiac output: atrial rhythm, } \\
\text { pulmonary vasodilator therapy, afterload } \\
\text { reduction, atrial fenestration } \\
\text { Enteric steroids } \\
\text { Diuretics } \\
\text { Heparin } \\
\text { High dose aldactone } \\
\text { Intravenous albumin and } \gamma \text {-globulin infusions } \\
\text { Immunosuppression } \\
\text { Cardiac transplantation }\end{array}$ \\
\hline Plastic bronchitis & $<2 \%$ & $\begin{array}{l}\text { Tachypnoea, cough, wheezing, } \\
\text { expectoration of bronchial casts }\end{array}$ & $\begin{array}{l}\text { Unknown; associated with leakage of } \\
\text { proteinaceous material into the airways } \\
\text { resulting in bronchial casts }\end{array}$ & $\begin{array}{l}\text { Urgent bronchial lavage } \\
\text { Pulmonary vasodilators } \\
\text { Cardiac transplantation }\end{array}$ \\
\hline $\begin{array}{l}\text { Primary ventricular } \\
\text { dysfunction }\end{array}$ & $\sim 7-10 \%$ & $\begin{array}{l}\text { Progressive exercise intolerance, } \\
\text { AV valve insufficiency, } \\
\text { hepatomegaly, ascites }\end{array}$ & $\begin{array}{l}\text { Chronic hypertrophy, abnormal ventricular } \\
\text { morphology (systemic right or indeterminate } \\
\text { ventricle), older age at repair, prolonged } \\
\text { cyanosis or volume overload, myocardial } \\
\text { perfusion abnormalities }\end{array}$ & $\begin{array}{l}\text { ACE inhibition } \\
\text { Pulmonary vasodilators } \\
\text { Calcium channel blockers for diastolic } \\
\text { dysfunction } \\
\beta \text {-blockers } \\
\text { Multisite pacing } \\
\text { Cardiac transplantation }\end{array}$ \\
\hline $\begin{array}{l}\text { Progressive increase in } \\
\text { pulmonary resistance }\end{array}$ & Unknown & Hypoxaemia & $\begin{array}{l}\text { Pulmonary arteriovenous malformations, } \\
\text { inadequate hepatic vein effluent, lack of } \\
\text { pulsatile flow }\end{array}$ & $\begin{array}{l}\text { Pulmonary vasodilators; stenting of } \\
\text { pulmonary arterial narrowing }\end{array}$ \\
\hline Hepato-renal insufficiency & & & Low cardiac output, sepsis & $\begin{array}{l}\text { Supportive care, optimise cardiac output, } \\
\text { high mortality }\end{array}$ \\
\hline Hepatic failure & Unknown & $\begin{array}{l}\text { Hepatomegaly, ascites; } \\
\text { hepatocellular carcinoma }\end{array}$ & Progression of chronic cardiac cirrhosis & Cardiac and liver transplantation \\
\hline
\end{tabular}


Table 3 Long term Fontan surveillance

\begin{tabular}{|c|c|c|}
\hline & Parameters & Monitoring \\
\hline Constitutional & $\begin{array}{l}\text { Adequate growth in childhood } \\
\text { Weight or muscle loss in adulthood } \\
\text { Avoid overweight } \\
\text { Blood pressure: normotensive } \\
\text { Functional classification, } \\
\text { Aerobic activity } \\
\text { Daily napping }\end{array}$ & $\begin{array}{l}\text { Aerobic activity } \\
\text { Exercise testing }\end{array}$ \\
\hline Cardiac haemodynamics & $\begin{array}{l}\text { Heart size } \\
\text { Atrial dilatation } \\
\text { Atriopulmonary anastomosis } \\
\text { Pulmonary narrowing, distortion } \\
\text { Pulmonary venous or atrioventricular (AV) } \\
\text { inflow obstruction } \\
\text { AV valve regurgitation or stenosis } \\
\text { Aortic insufficiency } \\
\text { Ventricular outflow obstruction } \\
\text { Arch obstruction } \\
\text { Ventricular function }\end{array}$ & $\begin{array}{l}\text { Echocardiogram } \\
\text { Periodic chest radiograph } \\
\text { Cardiac MRI or CT }\end{array}$ \\
\hline Rhythm & $\begin{array}{l}\text { Presence of atrial versus junctional rhythm } \\
\text { Resting heart rate } \\
\text { Chronotropic response to exertion } \\
\text { Arrhythmia development }\end{array}$ & Periodic $24 \mathrm{~h}$ ambulatory monitoring; event monitoring \\
\hline Pulmonary & $\begin{array}{l}\text { Hypoxaemia } \\
\text { Vascular resistance }\end{array}$ & Oxygen saturation, resting and exertional \\
\hline Endocrine & Thyroid function & Thyroid stimulating hormone (TSH), thyroxine (T4) \\
\hline Renal & & Blood urea nitrogen, creatinine \\
\hline Hepatic & $\begin{array}{l}\text { Hepatomegaly } \\
\text { Cardiac cirrhosis } \\
\text { Synthetic function }\end{array}$ & $\begin{array}{l}\text { Liver function: enzymes, coagulation } \\
\text { Abdominal ultrasound, CT or MR } \\
\text { Liver biopsy } \\
\text { Serum } \alpha \text {-fetoprotein }\end{array}$ \\
\hline Gastrointestinal & Bloating, distension, diarrhoea, ascites, gallstones & Stool $\alpha-1$ anti-trypsin \\
\hline Haematologic & Anaemia, polycythaemia, thrombocytopenia & Blood count, platelets \\
\hline Metabolic & & B-type natriuretic peptide, albumin, alkaline phosphatase \\
\hline Neurologic & $\begin{array}{l}\text { Cerebrovascular accident } \\
\text { Depression }\end{array}$ & \\
\hline
\end{tabular}

the collective memory of the earlier high mortality or prolonged hospital courses associated with primary Fontan surgery in past decades has made many clinicians reluctant to recommend additional interventions, particularly without overt symptoms.

In addition to standard haemodynamic evaluations, more global assessment of the impact of the Fontan physiology on other organ systems needs to become part of routine surveillance (table 2). It cannot be assumed that the patient has other healthcare providers with adequate knowledge of the impact of the Fontan circulation to monitor these systems. Growth failure in childhood and weight loss in adulthood are advanced manifestations of inadequate haemodynamic status. In adulthood, exercise intolerance may result in

\section{Management of the failing Fontan circulation: key points}

- Symptoms develop at an advanced stage of declining Fontan circulation.

- Identification of the 'failing' Fontan before the development of ascites or protein-losing enteropathy is essential to improve outcomes.

- Monitoring functional status, rhythm, serum biomarkers, and liver changes is essential to long term assessment of 'cardiac' status.

- Ablation procedures for atriopulmonary Fontan patients have a low likelihood of success.

- Aggressive therapy for rhythm and haemodynamic abnormalities may improve long term functional status. extremes of a sedentary lifestyle and result in obesity. By contributing to alterations in pulmonary function $^{\mathrm{w} 22}$ and increased systemic vascular resistance, overweight contributes rapidly to Fontan failure. Patients should be counselled on the importance of regular aerobic activity for conditioning, and avoidance of overweight as essential to limiting Fontan failure.

In the USA, the cardiologist caring for Fontan patients is now asked to routinely monitor and assess other organ systems, including haematologic, endocrine, pulmonary, hepatic and gastrointestinal, within the confines of decreased reimbursement for testing and shorter office visits. The barriers to sophisticated medical care for the older Fontan patient encompass difficulties in education of the patient relative to the need for regular cardiac care, availability of comprehensive integrated care centres with sufficient expertise, and in many countries the lack of healthcare coverage. Nonetheless, it is apparent that a change in practice for the routine long term follow-up of Fontan patients is necessary in order to detect progressive subtle decline in status and to have a favourable impact on the functional status of these unique survivors (table 3). Failure to change our standard methods of routine cardiac care in this setting constitutes a failure of optimal medical management. Chronic pulmonary vasodilator therapy, in addition to chronic diuresis, may become part of routine long term medical therapy as this population ages. ${ }^{\mathrm{w} 25}$ 


\section{You can get CPD/CME credits for Education in Heart}

Education in Heart articles are accredited by both the UK Royal College of Physicians (London) and the European Board for Accreditation in Cardiology-you need to answer the accompanying multiple choice questions (MCOs). To access the questions, click on BMJ Learning: Take this module on BMJ Learning from the content box at the top right and bottom left of the online article. For more information please go to: http://heart.bmj.com/misc/education.dtl

- RCP credits: Log your activity in your CPD diary online (http://www. rcplondon.ac.uk/members/CPDdiary/index.asp)-pass mark is $80 \%$.

- EBAC credits: Print out and retain the BMJ Learning certificate once you have completed the MCOs-pass mark is $60 \%$. EBAC/ EACCME Credits can now be converted to AMA PRA Category 1 CME Credits and are recognised by all National Accreditation Authorities in Europe (http://www.ebac-cme. org/newsite/?hit=men02).

Please note: The MCOs are hosted on BMJ Learning - the best available learning website for medical professionals from the BMJ Group. If prompted, subscribers must sign into Heart with their journal's username and password. All users must also complete a one-time registration on BMJ Learning and subsequently log in (with a BMJ Learning username and password) on every visit.

Better strategies for improving vascular endothelial function and liver protection, including the usage of polyphenols and thiazolidinediones, will become areas for future studies. ${ }^{\text {w26 }}$

Contributors Both authors contributed to the concept and writing of this article in terms of writing the text, literature review, and approval of the content, analysing the possible risk factors that may contribute to a patient's failing Fontan circulation. Their objective was to educate cardiologists and others who care for patients with single ventricular physiology of the warning signs that can lead to a failed Fontan circulation. Dr Deal is responsible for the overall content as guarantor of this article.

Competing interests In compliance with EBAC/EACCME guidelines, all authors participating in Education in Heart have disclosed potential conflicts of interest that might cause a bias in the article. The authors have no competing interests.

Provenance and peer review Commissioned; internally peer reviewed.

\section{REFERENCES}

1. Fontan $\mathbf{F}$, Baudet E. Surgical repair of tricuspid atresia. Thorax 1971;26:240-8.

- The surgery as described is obsolete, but worth reading for the comments on the longevity of homografts, perioperative management, and prediction of arrhythmias.

2. Hosein RB, Clarke AJ, McGuirk SP, et al. Factors influencing early and late outcome following the Fontan procedure in the current era. The 'Two Commandments'? Eur J Cardiothorac Surg 2007:31:344-53.

- An in-depth analysis of the key haemodynamic factors contributing to long term survival in a large series of Fontan patients.

3. d'Udekem Y, lyengar AJ, Cochrane AD, et al. The Fontan procedure: contemporary techniques have improved long-term outcomes. Circulation 2007;116(11 Suppl):1157-64.

- An excellent comparison of the long term outcomes of patients undergoing the three major types of Fontan modifications.

4. Cohen MS, Zak V, Atz AM, et al. Anthropometric measures after Fontan procedure: implications for suboptimal functional outcome. Am Heart J 2010;160:1092-8.
5. Fernandes SM, McElhinney DB, Khairy $P$, et al. Serial cardiopulmonary exercise testing in patients with previous Fontan surgery. Pediatr Cardiol 2010;31:175-80.

6. Diller GP, Giardini A, Dimopoulos K, et al. Predictors of morbidity and mortality in contemporary Fontan patients: results from a multicenter study including cardiopulmonary exercise testing in 321 patients. Eur Heart J 2010;31:3073-83.

- An excellent multicentre study of exercise testing in adolescents and young adults with Fontan physiology, and analysis of factors correlating with poor outcomes.

7. Baek JS, Bae EJ, Ko JS, et al. Late hepatic complications after Fontan operation; non-invasive markers of hepatic fibrosis and risk factors. Heart 2010;96:1750-5.

- In-depth review of results of hepatic imaging and functional testing in a large number of older Fontan patients, with indices correlating with hepatic complications.

8. van den Bosch $\mathbf{A E}$, Roos-Hesselink JW, van Domburg $R$, et al. Long-term outcome and quality of life in adult patients after the Fontan operation. Am J Cardiol 2004;93:1141-5.

- Although not a large number of patients, a thoughtful and comprehensive review of all complications encountered in a group of adult Fontan patients followed in a single centre.

9. Kim SJ, Kim WH, Lim HG, et al. Outcome of 200 patients after an extracardiac Fontan procedure. J Thorac Cardiovasc Surg 2008;136:108-16.

10. Giannakoulas G, Dimopoulos K, Yuksel S, et al. Atrial tachyarrhythmias late after Fontan operation are related to increase in mortality and hospitalization. Int J Cardiol 2010 Dec 31 [Epub ahead of print]

- A correlation of the impact of arrhythmias in adult Fontan patients on morbidity and mortality.

11. Stamm C, Friehs I, Mayer JE Jr, et al. Long-term results of the lateral tunnel Fontan operation. J Thorac Cardiovasc Surg 2001;121:28-41.

12. Lee JR, Kwak J, Kim KC, et al. Comparison of lateral tunnel and extracardiac conduit Fontan procedure. Interact Cardiovasc Thorac Surg 2007;6:328-30.

13. Nurnberg JH, Ovroutski S, Alexi-Meskishvili V, et al. New onset arrhythmias after the extracardiac conduit Fontan operation compared with the intraatrial lateral tunnel procedure: early and midterm results. Ann Thorac Surg 2004;78:1979-88.

14. Yap SC, Harris L, Silversides CK, et al. Outcome of intra-atrial reentrant tachycardia catheter ablation in adults with congenital heart disease. J Am Coll Cardiol 2010;56:1589-96.

- An excellent review of the outcomes of catheter ablation procedures for arrhythmias in adults with congenital heart disease, with discussion of factors associated with procedural success.

15. Mavroudis C, Backer CL, Deal BJ. Late reoperations for Fontan patients: state of the art invited review. Eur J Cardiothorac Surg 2008;34:1034-40.

- A detailed review of arrhythmia mechanisms, surgical techniques, anatomic variants, and discussion of outcomes in a large group of Fontan patients undergoing surgical conversion and arrhythmia surgery.

16. Mavroudis C, Deal BJ, Backer CL, et al. 111 Fontan conversions with arrhythmia surgery: surgical lessons and outcomes. Ann Thorac Surg 2007;84:1457-66.

17. Nakamura Y, Yagihara T, Kagisaki K, et al. Ventricular performance in long-term survivors after Fontan operation. Ann Thorac Surg 2011;91:172-80.

18. Khairy P, Fernandes SM, Mayer JE Jr, et al. Long-term survival modes of death, and predictors of mortality in patients with Fontan surgery. Circulation 2008;117:85-92.

- An in-depth analysis of all-cause mortality in a large group of Fontan patients operated on in a single centre before 1985.

19. Davies RR, Chen JM, Mosca RS. The Fontan procedure: evolution in technique: attendant imperfections and transplantation for "failure". Semin Thorac Cardiovasc Surg Pediatr Card Surg Annu 2011:14:55-66.

- An excellent discussion of the physiology of surgical Fontan modifications and long term complications, and review of outcomes from transplantation.

20. Bernstein D, Naftel D, Chin C, et al. Outcome of listing for cardiac transplantation for failed Fontan: a multi-institutional study. Circulation 2006;114:273-80. 